\title{
Steady-State Creep Behavior of Super304H Austenitic Steel at Elevated Temperatures
}

\author{
Ping Ou ${ }^{1,2} \cdot$ Long $\mathrm{Li}^{1} \cdot$ Xing-Fei Xie ${ }^{1} \cdot J_{\text {ian } \mathrm{Sun}^{1}}$
}

Received: 28 July 2015/Revised: 17 September 2015/Published online: 17 November 2015

(C) The Chinese Society for Metals and Springer-Verlag Berlin Heidelberg 2015

\begin{abstract}
Creep behavior of Super304H austenitic steel has been investigated at elevated temperatures of 923-973 K and at applied stress of 190-210 MPa. The results show that the apparent stress exponent and activation energy in the creep deformation range from 16.2 to 27.4 and from 602.1 to $769.3 \mathrm{~kJ} / \mathrm{mol}$ at different temperatures, respectively. These high values imply the presence of a threshold stress due to an interaction between the dislocations and $\mathrm{Cu}$-rich precipitates during creep deformation. The creep mechanism is associated with the dislocation climbing governed by the matrix lattice diffusion. The origin of the threshold stress is mainly attributed to the coherency strain induced in the matrix by $\mathrm{Cu}$-rich precipitates. The theoretically estimated threshold stresses from $\mathrm{Cu}$-rich precipitates agree reasonably with the experimental results.
\end{abstract}

KEY WORDS: Super304H steel; Cu-rich precipitate; Creep; Threshold stress

\section{Introduction}

Super304H austenitic steel is based on $18 / 8 \mathrm{Cr}-\mathrm{Ni}$ stainless steel alloyed mainly with about $3 \% \mathrm{Cu}$ and a small amount of $\mathrm{Nb}$, which is widely used in ultra-super critical (USC) power plants due to its excellent high-temperature performance, especially the outstanding high-temperature creep resistance $[1,2]$. The outstanding strength at high temperatures of the Super304H steel arises from the precipitation of nanosized $\mathrm{Cu}$-rich and $M X(\mathrm{Nb}(\mathrm{C}, \mathrm{N}))$ phases in

Available online at http://link.springer.com/journal/40195

Jian Sun

jsun@sjtu.edu.cn

1 Shanghai Key Laboratory of Advanced High-Temperature Materials and Precision Forming, School of Materials Science and Engineering, Shanghai Jiaotong University, Shanghai 200240, China

2 School of Materials Science and Engineering, Jiangxi University of Science and Technology, Ganzhou 341000, China the austenitic matrix during service at high temperatures [1]. The nanosized $\mathrm{Cu}$-rich phase with a coherent crystallographic relationship with the austenitic matrix has been regarded to be of the most significant precipitationstrengthening effect in the Super304H steel [3, 4]. The hardening and tensile yielding behaviors of the aged Super304H steels have been systematically investigated previously, and it was found that the strengthening of the $\mathrm{Cu}$-rich precipitates arises mainly from the coherency strain and partially from stacking fault in the Super304H steel when the $\mathrm{Cu}$-rich precipitates were considered as small weak closely spaced precipitates, and gliding dislocations shear $\mathrm{Cu}$-rich precipitates rather than bypass them in the steel $[5,6]$. It has been well known that there is considerable evidence for the presence of a resisting stress in high-temperature creep for the precipitation- or dispersion-strengthened alloys [7-17], where the resisting stress is a measure of resistance to dislocation motion caused by the strengthening particles and other obstacles to dislocation motion [18]. The resisting stress or threshold stress arising from an interaction between dislocations and precipitates can be attributed to Orowan or climbing bypass 
mechanism [19, 20]. For example, some researchers investigated the threshold stress creep in precipitationstrengthened aluminum alloys, and the threshold stresses were attributed to lattice strains induced in the matrix by the coherent precipitates due to a size misfit that affects the dislocation climb rate $[7,9,21]$. Up to now, the precipitation-strengthening effect of the $\mathrm{Cu}$-rich phases in the Super304H steel during creep deformation at elevated temperatures is rarely reported in the literature. In this paper, the creep behavior of the Super304H steel has been investigated by creep tests at elevated temperatures of 923-973 K and at applied stress of 190-210 MPa. The precipitation-strengthening mechanism of the $\mathrm{Cu}$-rich phases in the Super304H steel during creep deformation at elevated temperatures was analyzed in light of the creep theory proposed for precipitation- or dispersion-strengthened alloys [7-21].

\section{Experimental}

The solution-treated Super304H austenitic steel supplied by a steel plant was adopted in the present work. The chemical composition of the Super304H steel is given in Table 1. In order to maintain the consistency of microstructure of the Super304H steel for creep tests at different temperatures, all of the specimens were aged at $973 \mathrm{~K}$ for $500 \mathrm{~h}$ followed by air cooling. The dog-bone specimens with a gauge diameter of $5 \mathrm{~mm}$ and a gauge length of $25 \mathrm{~mm}$ were fabricated for creep tests. The creep tests were carried out at elevated temperatures of 923-973 K and at applied stress of 190-210 MPa in air on the creep test machine (RDL-50, Jinan, China). The microstructure of aged Super304H steel was examined by means of JSM-7600F field emission scanning electron microscope (SEM) and JEOL 2100F transmission electron microscope (TEM) with energy-dispersive X-ray spectrometer (EDS). The samples for SEM observations were prepared by mechanical polishing and then etching in an aqua regia solution for $15 \mathrm{~s}$, and the samples for TEM observations were prepared by twin-jet electropolishing in a $5 \mathrm{vol} \%$ perchloric acid and $95 \mathrm{vol} \%$ ethanol solution at $233-243 \mathrm{~K}$ and at $60 \mathrm{~V}$. The average diameter of Cu-rich particles was determined from TEM images taken along the [011] zone axis for the Super304H steel aged at $973 \mathrm{~K}$ for $500 \mathrm{~h}$. The number of the density per unit area, $N_{\mathrm{s}}$, of
$\mathrm{Cu}$-rich particles was also measured to calculate the volume fraction of the particles in the austenitic matrix. More than 200 particles were examined for the aged Super304H steel.

\section{Results and Discussion}

\subsection{Microstructure}

Figure 1a shows the SEM microstructure of the aged Super304H steel, where equiaxed austenitic grains with an average diameter of about $15 \mu \mathrm{m}$ and some primary carbides with a large size within grains and the carbides distributed densely at grain boundaries can be observed. The EDS result shown in Fig. 1b indicates that the primary carbides are Nb-rich $M X$ phases. Figure 2 shows the TEM image of the aged steel, in which a large number of spherical precipitates can be found. The average diameter was measured to be about $26 \mathrm{~nm}$. The EDS analysis indicates that the spherical precipitates are $\mathrm{Cu}$-rich phases. The obvious coffee-bean contrast feature exhibits that the $\mathrm{Cu}$ rich spherical precipitates are coherent with the austenitic matrix. The cubic/cubic crystallographic relationship and coherency interface between the $\mathrm{Cu}$-rich spherical precipitates and austenitic matrix were further confirmed by highresolution TEM as shown in Fig. 3a. No extra diffraction spots besides those of the austenitic matrix were observed from the corresponding fast Fourier transformation (FFT) diffractogram as shown in Fig. 3b, which implies a small lattice parameter mismatch $\delta(\Delta a / a)$ between the $\mathrm{Cu}$-rich precipitates and the austenitic matrix. The discontinuous chains of the carbides at the grain boundaries were found to be $M_{23} \mathrm{C}_{6}$ by TEM [3, 4, 22]. The polygonal-shaped Nbrich $M X$ precipitates with a nanosized diameter were only found within the grains occasionally in the aged Super304H steel by TEM [22]. Those observations show that Nb-rich $M X$ phases were not thoroughly dissolved in the solution treatment and therefore cannot fully precipitate in the aging treatment for the Super304H steel.

\subsection{Creep Behavior and Threshold Stress}

The aged Super304H steel underwent creep deformation at elevated temperatures of 923-973 K and at applied stress of $190-210 \mathrm{MPa}$, respectively. The creep curves of the

Table 1 Chemical composition of the Super304H steel (wt $\%$ )

\begin{tabular}{lllllllllllll}
\hline $\mathrm{C}$ & $\mathrm{Mn}$ & $\mathrm{P}$ & $\mathrm{S}$ & $\mathrm{Si}$ & $\mathrm{Ni}$ & $\mathrm{Cr}$ & $\mathrm{Cu}$ & $\mathrm{Nb}$ & $\mathrm{N}$ & $\mathrm{Al}$ & $\mathrm{B}$ & $\mathrm{Fe}$ \\
\hline 0.08 & 0.787 & 0.022 & 0.001 & 0.29 & 8.88 & 17.98 & 3.066 & 0.58 & 0.07 & 0.012 & 0.0026 & $\mathrm{Bal}$. \\
\hline
\end{tabular}



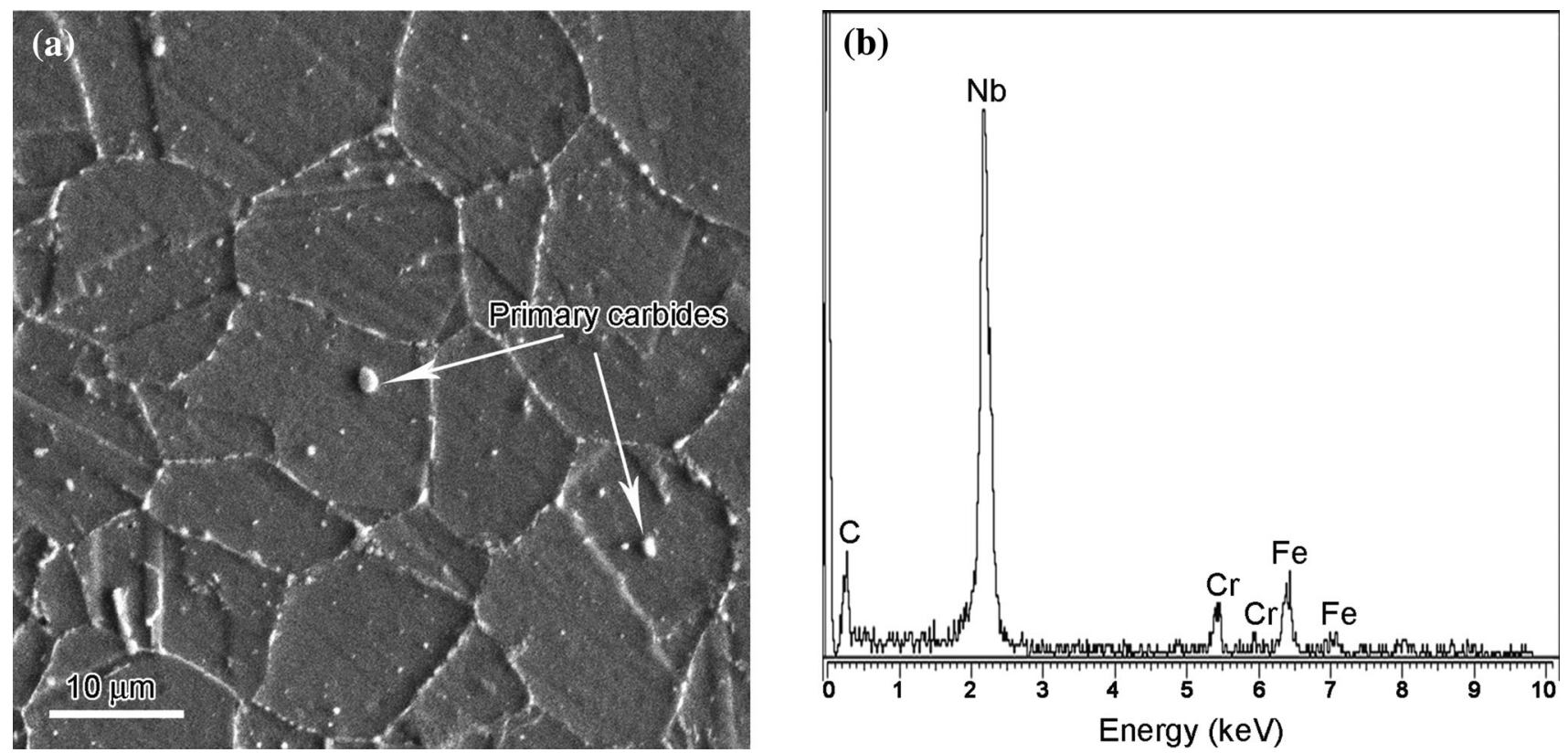

Fig. 1 SEM microstructure of the aged Super304H steel a and EDS result of the primary $M X$ particles b

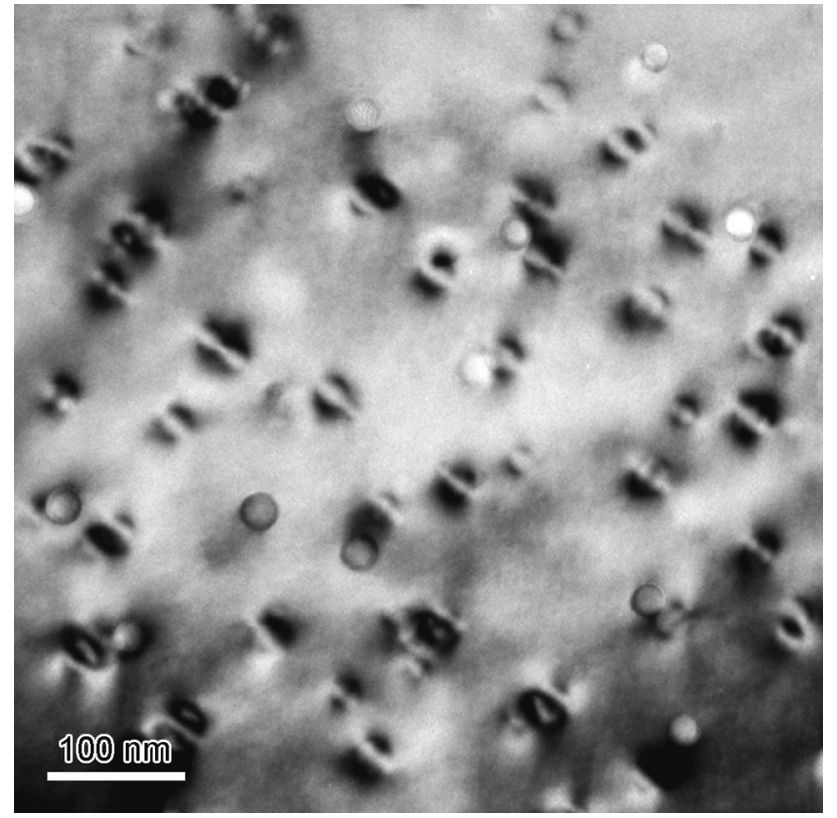

Fig. 2 Diffraction contrast image of $\mathrm{Cu}$-rich precipitates in Super304H steel aged at $973 \mathrm{~K}$ for $500 \mathrm{~h}$

Super304H steel exhibit the occurrence of a short primary stage followed by the secondary steady stage of creep. The creep behavior of metallic materials generally follows a power-law equation $[23,24]$ :

$\dot{\varepsilon}=\frac{A \mu b D_{0}}{k T}\left(\frac{\sigma}{\mu}\right)^{n_{\mathrm{a}}} \exp \left(-\frac{Q_{\mathrm{a}}}{R T}\right)$,

where $\dot{\varepsilon}$ is the steady creep strain rate, $A$ the dimensionless constant, $D_{0}$ the frequency factor for diffusion, $k$ the Boltzmann's constant, $\sigma$ the applied stress, $n_{\mathrm{a}}$ the apparent stress exponent, $Q_{\mathrm{a}}$ the apparent activation energy for creep, $R$ the gas constant, $T$ the absolute temperature, $\mu$ and $b\left(\sqrt{2} a_{\gamma} / 2\right)$ are the shear modulus and Burgers vector of dislocation of the austenitic matrix, respectively. The shear modulus $\mu$ of the Super304H steel is given as

$\mu=\frac{E}{2(1+v)}$,

where $v=0.29$ is the Poisson's ratio, $E$ is the Young's modulus of the austenitic matrix. The Young's modulus $E$ at different temperatures was calculated in terms of the linear relationship between the Young's modulus and temperature of the Super304H steel [25], as given in Table 2. Thus, the temperature-dependent shear modulus $\mu$ can be calculated by Eq. (2), which is given in Table 2 . The relationship between $\ln \dot{\varepsilon}$ and $\ln (\sigma / \mu)$ at different temperatures, where the applied stress was normalized with the shear modulus, is shown in Fig. 4. It can be seen that the plot of $\ln \dot{\varepsilon}$ versus $\ln (\sigma / \mu)$ is linear at each temperature. The slopes, those are, the apparent stress exponent at creep temperatures of 923,948 and $973 \mathrm{~K}$, were estimated to be about 27.4, 21.0 and 16.2 for the Super304H steel, respectively, which are much higher than that of the 18/8 $\mathrm{Cr}-\mathrm{Ni}$ austenitic stainless steel $\left(n_{\mathrm{a}}=5\right)$ [26]. The Arrhenius plots of $\ln \dot{\varepsilon}$ versus $1 / T$ are shown in Fig. 5. These plots yield the apparent activation energy of 769.3, 690.4 and $602.1 \mathrm{~kJ} / \mathrm{mol}$ for creep deformation at temperatures of 923 , 948 and $973 \mathrm{~K}$, respectively, which are markedly higher in 

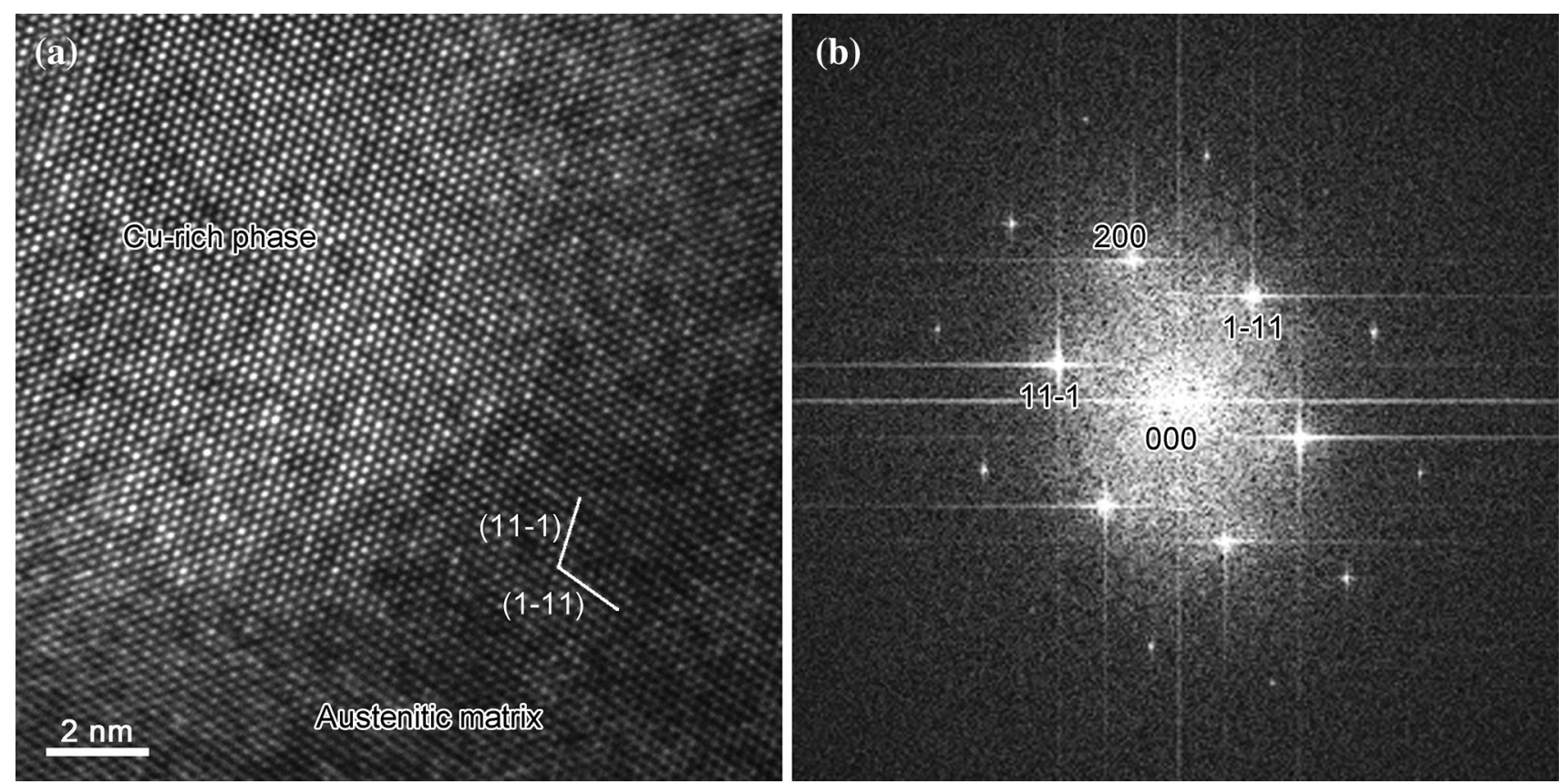

Fig. 3 High-resolution TEM image a and corresponding FFT diffractogram b of Cu-rich precipitate in Super304H steel aged at $973 \mathrm{~K}$ for $500 \mathrm{~h}$

Table 2 Young's modulus, shear modulus of the austenitic matrix and experimental threshold stress $\sigma_{\text {th }}$ at different temperatures

\begin{tabular}{llll}
\hline Temperature $(\mathrm{K})$ & $E(\mathrm{GPa})$ & $\mu(\mathrm{GPa})$ & Experimental $\sigma_{\text {th }}(\mathrm{MPa})$ \\
\hline 923 & 138 & 53.5 & 162.7 \\
948 & 136 & 52.7 & 152.9 \\
973 & 134 & 51.9 & 137.4 \\
\hline
\end{tabular}

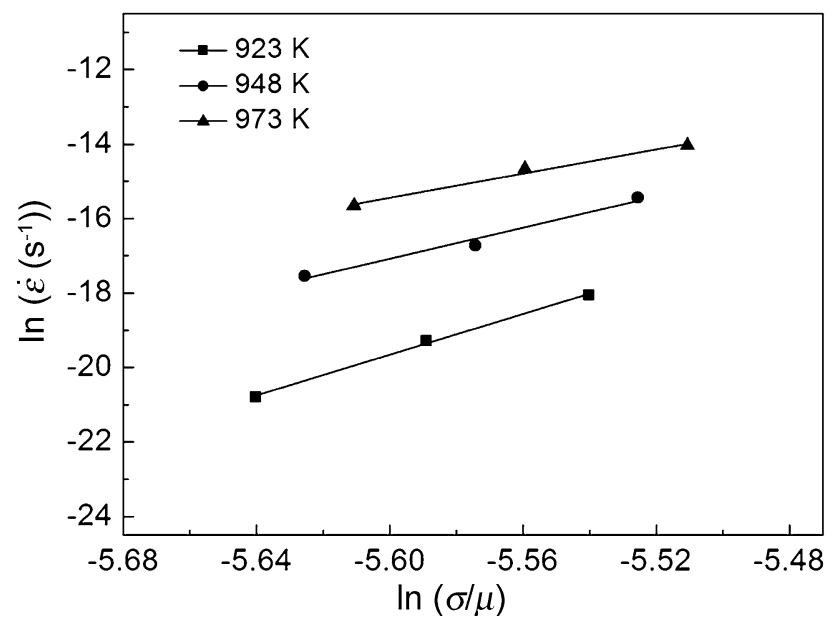

Fig. 4 Plots of $\ln \dot{\varepsilon}$ versus $\ln (\sigma / \mu)$ for the Super304H steel crept at different temperatures

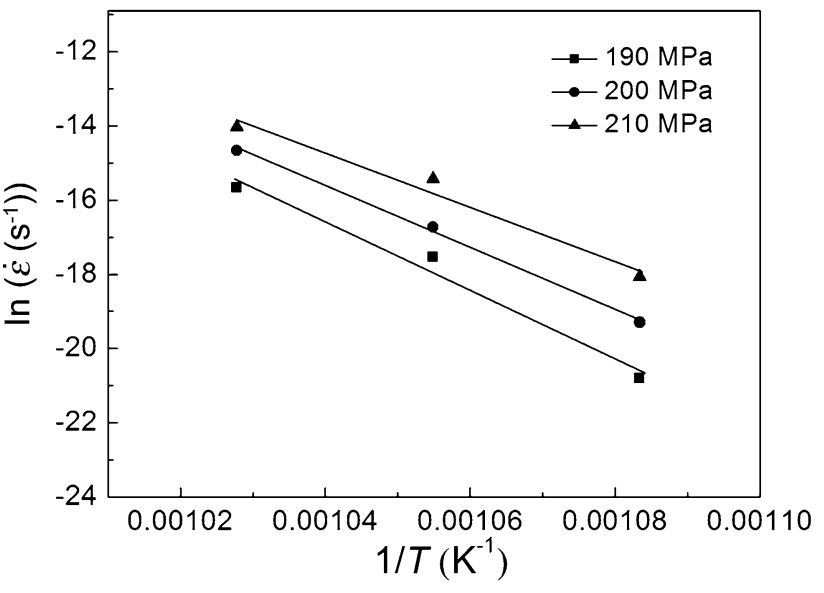

Fig. 5 Plots of $\ln \dot{\varepsilon}$ versus $1 / T$ for the Super304H steel crept at different applied stresses

comparison with that for lattice diffusion in the $18 / 8 \mathrm{Cr}-\mathrm{Ni}$ austenitic stainless steel $(280 \mathrm{~kJ} / \mathrm{mol})$ [27]. The observed higher apparent stress exponent results from an interaction between dislocations and $\mathrm{Cu}$-rich precipitates. To overcome the barriers of dislocation motion requires higher activation energy during creep deformation of the Super304H steel.

When the apparent stress exponent and apparent activation energy of the Super304H steel significantly exceed those of the matrix, an a thermal threshold stress, $\sigma_{\text {th }}$, 
should be considered, which is a measurement of resistance stress to dislocation motion caused by the strengthening particles. This leads to a modified power-law equation [28]:

$\dot{\varepsilon}=\frac{A_{1} \mu b D_{0}}{k T}\left(\frac{\sigma-\sigma_{\mathrm{th}}}{\mu}\right)^{n} \exp \left(-\frac{Q}{R T}\right)$,

where $A_{1}$ is the dimensionless constant, $n$ the true stress exponent, $Q$ the true activation energy for creep, and the rest symbols in Eq. (3) have the same meanings as those indicated in Eq. (1). The value of $\sigma_{\text {th }}$ can be derived from a linear plot of $\dot{\varepsilon}^{1 / n}$ versus $\sigma$ when $\dot{\varepsilon}^{1 / n}$ is extrapolated to zero. A set of values $n=2,3,5$ was used to fit the experimental data, since they are usually associated with several different creep mechanisms, such as grain boundary sliding, dislocation viscous glide and dislocation climbing, respectively. Figure 6 shows the plots of $\dot{\varepsilon}^{1 / 5}$ versus $\sigma$ for the Super304H steel. It can be seen that the plots of $\dot{\varepsilon}^{1 / 5}$ versus $\sigma$ can be satisfactorily fitted by straight lines, from which the threshold stress $\sigma_{\text {th }}$ was estimated at different temperatures for the Super304H steel, as given in Table 2. For the Super304H steels, the values of the coefficient of matrix lattice diffusion at different temperatures can be obtained using the relation:

$D=D_{0} \exp (-Q / R T)$

where $D_{0}=3.7 \times 10^{-5} \mathrm{~m}^{2} / \mathrm{s}$ and $Q=280 \mathrm{~kJ} / \mathrm{mol}$ are the frequency factor and activation energy for matrix lattice diffusion, respectively, in the $18 / 8 \mathrm{Cr}-\mathrm{Ni}$ austenitic steel [27]. Figure 7 shows that a relation of the minimum creep strain rate $\dot{\varepsilon}$ normalized to coefficient of matrix lattice diffusion in a plot of $\ln (\dot{\varepsilon} / D)$ versus $\ln \left[\left(\sigma-\sigma_{\text {th }}\right) / \mu\right]$. It can be seen that the data for all the temperatures can be fitted well by a single straight line, which strongly suggests the matrix lattice diffusion governs the creep strain rate-

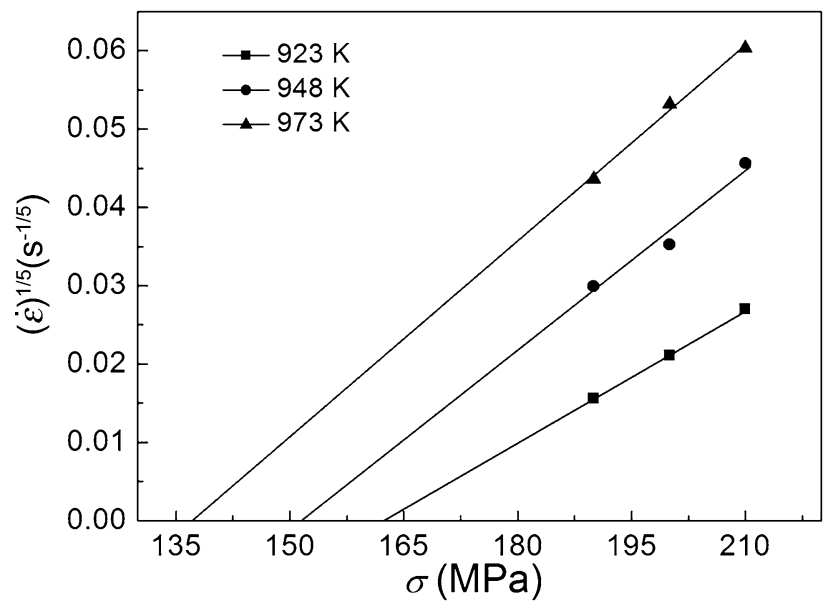

Fig. 6 Plots of $\dot{\varepsilon}^{1 / 5}$ versus $\sigma$ for the Super304H steel crept at different temperatures

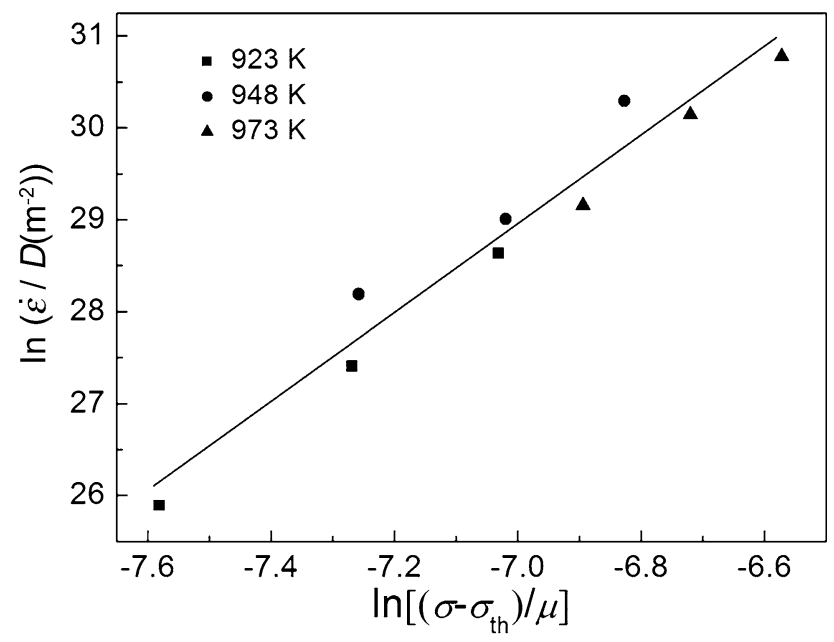

Fig. 7 Plot of $\ln (\dot{\varepsilon} / D)$ versus $\ln \left[\left(\sigma-\sigma_{\text {th }}\right) / \mu\right]$ for the Super304H steel

controlling process. The slope of the straight line, i.e., the value of the true stress exponent $n$, is close to 5 , as shown in Fig. 7. Thus, the creep mechanism can be considered as dislocation climbing for the Super304H steel underwent creep deformation at elevated temperatures of 923-973 K and at applied stress of 190-210 MPa.

The temperature dependence of the normalized threshold stresses $\sigma_{\mathrm{th}} / \mu$ can be expressed as [29, 30]:

$\frac{\sigma_{\mathrm{th}}}{\mu}=A_{2} \exp \left(\frac{Q_{\mathrm{th}}}{R T}\right)$

where $A_{2}$ is a constant and $Q_{\mathrm{th}}$ is the energy associated with the bindings between the dislocations and the obstacles giving rise to the threshold stress. The activation energy, $Q_{\text {th }}$, was obtained by plotting $\ln \left(\sigma_{\text {th }} / \mu\right)$ versus $T^{-1}$, as shown in Fig. 8. The slope of the line is about $21 \mathrm{~kJ} / \mathrm{mol}$. This small value of $Q_{\text {th }}$ is most likely effective activation energy for a complex physical process for dislocation bypassing the $\mathrm{Cu}$-rich precipitates in the Super304H steel.

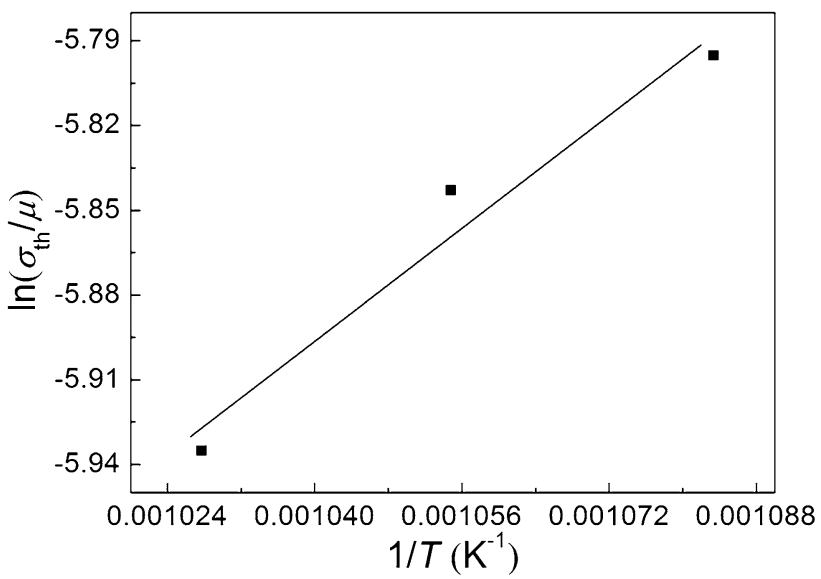

Fig. 8 Plot of $\ln \left(\sigma_{\mathrm{th}} / \mu\right)$ versus $1 / T$ for the Super304H steel 


\subsection{Origin of Threshold Stress}

The results indicate that the dislocation climbing governs the creep strain rate-controlling process and the threshold stress arises from dislocation bypassing the $\mathrm{Cu}$-rich precipitates in the Super304H steel during creep deformation. TEM results show that the $\mathrm{Cu}$-rich phase precipitates are coherent with the austenitic matrix in the Super304H steel. If the precipitates exhibit a positive lattice parameter mismatch with the matrix, as in the present case, elastic interactions with the dislocations make the climbing bypass more difficult, as modeled by Krug et al. [9]. They proposed that the dislocation that climbs to the apex of the precipitate by vacancy-mediated diffusion becomes trapped close to this position by a stress induced in the matrix with the positive lattice-parameter-mismatching precipitate, where the dislocation cannot escape the precipitate, as it can climb neither over nor under the region of departureside stress. Only the application of externally applied stress (the threshold stress) produces a shear force (the threshold force $F_{\mathrm{g}}$ ) that allows escaping of the dislocation. In the Super304H steel, the $\mathrm{Cu}$-rich precipitates exhibit a positive lattice parameter mismatch with the austenitic matrix. Thus, the glide forces $F_{\mathrm{g}}$ due to lattice parameter mismatch attract the dislocation to the precipitate, which impede the dislocation to escape the precipitate. The glide force $F_{\mathrm{g}}$ due to lattice parameter mismatch between the $\mathrm{Cu}$-rich precipitates and the austenitic matrix can be calculated using the Peach-Koehler equation [31]:

$F_{\mathrm{g}}=2 \mu \varepsilon b r^{3} \frac{3 y z}{\left(y^{2}+z^{2}\right)^{5 / 2}} 2 r$

where $r$ is the average radius of the $\mathrm{Cu}$-rich precipitates, $y$ the glide direction of a dislocation, and $z$ the glide plane height from the center of the precipitate where the dislocation climbs over it. When the dislocation climbs to the apex of the precipitate, the value of $z$ is equal to $r$. The coherency strain $\varepsilon$ is given as

$\varepsilon=\frac{3 B \delta}{3 B+2 E /(1+v)}$,

where $B$ is the bulk modulus of the $\mathrm{Cu}$-rich precipitate. The temperature-dependent bulk modulus $B$ of the $\mathrm{Cu}$-rich precipitate is given in Table 3, which given in the literature [32]. The lattice parameter mismatch $\delta$ was calculated to be $0.50 \%$ using the lattice parameter of $0.3615 \mathrm{~nm}$ of pure $\mathrm{Cu}$ [33] and of $0.3597 \mathrm{~nm}$ of Super304H steel at room temperature $[34,35]$. Using the mean thermal expansion coefficient of pure $\mathrm{Cu}$ [36] and 304 austenitic steel [37], the value of mismatch parameter $\delta$ at different temperatures can be achieved as given in Table 3. Thus, the coherency strain $\varepsilon$ can be calculated by Eq. (7), which is given in Table 3.

The maximum glide attractive force $F_{\mathrm{g}(\max )}$ due to lattice parameter mismatch with the austenitic matrix felt by a dislocation at the apex of a $\mathrm{Cu}$-rich precipitate can be estimated using Eq. (6). When the value of $y$ is equal to $r / 2$, the glide attractive force $F_{\mathrm{g}}$ reaches the maximum. Correspondingly, the threshold stress on the dislocation is given by the expression:

$\sigma_{\text {th }}=M F_{\mathrm{g}(\max )} / b L$,

where $M=3.06$ is the Taylor factor for fcc structures [38], $L=r(2 \pi / 3 f)^{1 / 2}$ is the mean spacing between neighboring precipitates, the volume fraction of the precipitates $f=2 \pi N_{\mathrm{s}} r^{2} / 3$. The volume fraction $f$ of the $\mathrm{Cu}$-rich precipitates was measured to be about $1.9 \%$ from TEM micrographs, and the average radius $r$ of the precipitate is about $13 \mathrm{~nm}$. Using the lattice parameter of $0.3597 \mathrm{~nm}$ of the Super304H steel at room temperature $[34,35]$ and the mean thermal expansion coefficient for 304 austenitic steel [37], the value of Burgers vector $b$ can be evaluated at different temperatures, which is given in Table 3. Thus, the theoretical threshold stress $\sigma_{\text {th }}$ from lattice parameter mismatch at different temperatures can be estimated by Eqs. (6) and (8), as also given in Table 3. It can be seen that the theoretical threshold stresses at different temperatures, resulting from strengthening of $\mathrm{Cu}$-rich precipitates, are in a reasonable agreement with the experimental results. If the Orowan bypass is considered as the possible mechanism for the origin of the threshold stress in the Super304H steel during creep deformation, the threshold stress for the dislocations to bypass the $\mathrm{Cu}$-rich precipitates can be estimated by the Orowan equation [39]:

$\sigma_{\mathrm{Or}}=M \frac{0.8 \mu b}{L}$.

Table 3 Bulk modulus of the $\mathrm{Cu}$-rich precipitate, lattice parameter mismatch and coherency strain between the Cu-rich precipitate and austenitic matrix, Burgers vector of the austenitic matrix, theoretical threshold stress $\sigma_{\text {th }}$ and Orowan stress $\sigma_{\text {Or }}$ at different temperatures

\begin{tabular}{lllllll}
\hline Temperature $(\mathrm{K})$ & $B(\mathrm{GPa})$ & $\delta(\%)$ & $\varepsilon(\%)$ & $b(\mathrm{~nm})$ & Theoretical $\sigma_{\text {th }}(\mathrm{MPa})$ & $\sigma_{\text {Or }}(\mathrm{MPa})$ \\
\hline 923 & 110.2 & 0.487 & 0.2975 & 0.2574 & 159.3 & 250.8 \\
948 & 109.3 & 0.488 & 0.2982 & 0.2576 & 157.3 & 247.3 \\
973 & 108.0 & 0.485 & 0.2925 & 0.2577 & 152.0 & 243.6 \\
\hline
\end{tabular}


The estimated Orowan stresses are also listed in Table 3. It is seen that Orowan stresses decrease with increasing temperature and are much higher than the experimental results. Thus, the threshold stress cannot be attributed to Orowan bypass mechanism under the creep deformation at elevated temperatures for the Super304H steel.

It is noteworthy that the creep mechanism is different at different applied stress regimes at given temperatures for the alloys. Satyanarayana et al. [11] investigated the creep behavior of $\mathrm{Fe}-\mathrm{Ni}-\mathrm{Cr}-\mathrm{Al}$ alloy hardened by $\mathrm{NiAl}$ precipitates at elevated temperatures. They found that the stress dependence of steady-state creep rate can be represented by a power law with two distinct regimes of creep deformation. The resisting stresses or threshold stresses in the high stress regime are larger than those in the low stress regime at elevated temperatures [11]. Correspondingly, the creep mechanism changes from Orowan bypass in the high stress regime to climbing bypass of the dislocations assisted by dislocation core diffusion in the low stress regime [11]. The present results indicated that the dislocation climbing governs the creep deformation at elevated temperatures of 923-973 K and at applied stress of 190-210 MPa for the Super304H steel. The threshold stress arises from dislocation bypassing the $\mathrm{Cu}$-rich precipitates in the Super304H steel during creep deformation. The creep deformation mechanism probably changes at low applied stresses at elevated temperatures for the Super304H steel. Recently, Park et al. [40, 41] investigated the creep behavior of solution-treated Super304H steel containing $\mathrm{Nb}$ and $\mathrm{V}$, and they found that the $\mathrm{V}$-rich $\mathrm{Z}$-phase and $M X$ phase with the nanosized diameter precipitate in the austenitic matrix during creep and assumed that those nanosized carbides give a beneficial effect on the creep strength. The nanosized incoherent $\mathrm{Nb}$-rich $M X$ phases have already been found to precipitate particularly at $\mathrm{Cu}$-rich phases and dislocation lines in the austenitic matrix during creep deformation at high temperature in the Super304H steel used in the present work [42]. As described above, there are primary Nb-rich $M X$ phases in the aged Super304H steel. The dispersed Nb-rich $M X$ precipitates with a nanosized diameter were hardly found in the austenitic matrix of the Super304H steel after aging by TEM, as shown in Fig. 2. The dispersed Nb-rich $M X$ particles will certainly play a role in precipitation strengthening in addition to the coherent $\mathrm{Cu}$-rich precipitates in the Super304H steel. However, in the present situation, it is hard to estimate the contribution of the $M X$ phases to the creep strength in the Super304H steel due to their heterogeneous distribution.

\section{Conclusions}

Creep behavior of Super304H austenitic steel has been investigated at elevated temperatures of 923-973 K and at applied stress of 190-210 MPa. The results show that the apparent stress exponent and activation energy in creep deformation range from 16.2 to 27.4 and from 602.1 to $769.3 \mathrm{~kJ} / \mathrm{mol}$ at different temperatures, respectively. The high values of average apparent stress exponent and activation energy for creep deformation mean that there is a threshold stress due to an interaction between the dislocations and $\mathrm{Cu}$-rich precipitates in creep deformation. The creep deformation mechanism is associated with the dislocation climbing process controlled by the matrix lattice diffusion. The origin of the threshold stress is mainly attributed to the coherency strain induced by the $\mathrm{Cu}$-rich precipitates in the matrix due to a positive lattice parameter mismatch. The calculated threshold stresses from $\mathrm{Cu}$-rich precipitates are in a reasonable agreement with the experimental results determined by the creep tests.

Acknowledgments This work was financially supported by the National Natural Science Foundation of China (No. 50931003) and the Shanghai Science and Technology Committee (No. 13dz2260300).

\section{References}

[1] Y. Sawaragi, S. Hirano, in Mechanical Behaviour of Materials, ed. by M. Jono, T. Inone (Pergamon Press, London, 1992), pp. 589-594

[2] R. Viswanathan, J.F. Henry, J. Tanzosh, G. Stanko, J. Shingledecker, B. Vitalis, R. Purgert, J. Mater. Eng. Perform. 14, 281 (2005)

[3] C.Y. Chi, H.Y. Yu, J.X. Dong, W.Q. Liu, S.C. Cheng, Z.D. Liu, X.S. Xie, Prog. Nat. Sci. 22, 175 (2012)

[4] C.Y. Chi, H.Y. Yu, J.X. Dong, X.S. Xie, Z.Q. Cui, X.F. Chen, F.S. Lin, Acta Metall. Sin. (Engl. Lett.) 24, 141 (2011)

[5] P. Ou, H. Xing, X.L. Wang, J. Sun, Mater. Sci. Eng. A 600, 171 (2014)

[6] P. Ou, H. Xing, X.L. Wang, J. Sun, Z.Q. Cui, C.S. Yang, Metall. Mater. Trans. A 46, 3909 (2015)

[7] E.A. Marquis, D.C. Dunand, Scr. Mater. 47, 503 (2002)

[8] C.B. Fuller, D.N. Seidman, D.C. Dunand, Acta Mater. 51, 4803 (2003)

[9] M.E. Krug, D.C. Dunand, Acta Mater. 59, 5125 (2011)

[10] P. Zhang, Scr. Mater. 52, 277 (2005)

[11] D.V.V. Satyanarayana, G. Malakondaiah, D.S. Sarma, Mater. Sci. Eng. A 323, 119 (2002)

[12] W.G. Zhao, J.G. Wang, H.L. Zhao, D.M. Yao, Q.C. Jiang, Mater. Sci. Eng. A 515, 10 (2009)

[13] V.C. Nardone, J.R. Strife, Metall. Trans. A 18, 109 (1987)

[14] F.A. Mohamed, K.T. Park, E.J. Lavernia, Mater. Sci. Eng. A 150, 21 (1992)

[15] J. Čadek, H. Oikawa, V. Šustek, Mater. Sci. Eng. A 190, 9 (1995)

[16] R.S. Mishra, A.B. Pandey, A.K. Mukherjee, Mater. Sci. Eng. A 201, 205 (1995) 
[17] K.T. Park, E.J. Lavernia, F.A. Mohamed, Acta Metall. Mater. 38, 2149 (1990)

[18] P.L. Threadgill, B. Wilshire, Creep Strength in Steel and High Temperature Alloys (The Metal Society, London, 1972), p. 8

[19] J. Cadek, Creep in Metallic Materials (Elsevier, Amsterdam, 1988)

[20] F.R.N. Nabarro, H.L. Villiers, The Physics of Creep: Creep and Creep-resistant Alloys (Taylor \& Francis, London, 1995)

[21] K.E. Knipling, D.C. Dunand, Scr. Mater. 59, 387 (2008)

[22] P. Ou, J. Sun, Z.Q. Cui, C.S. Yang, Trans. Mater. Heat Treat. 35, 85 (2014). (in Chinese)

[23] Z.Y. Ma, S.C. Tjong, X.M. Meng, J. Mater. Res. 17, 2307 (2002)

[24] J. Weertman, J. Appl. Phys. 26, 1213 (1955)

[25] H.C. Yang, Dongfang Boiler 2, 13 (2003). (in Chinese)

[26] F.R. Beckitt, T.M. Banks, T. Gladman, Creep Strength in Steel and High-Temperature Alloys (The Metals Society, London, 1974)

[27] H.J. Frost, M.F. Ashby, Deformation-Mechanism Maps: The Plasticity and Creep of Metals and Ceramics (Pergamon Press, London, 1982)

[28] Y. Li, T.G. Langdon, Acta Mater. 45, 4797 (1997)

[29] M.A. Morris, Philos. Mag. A 65, 943 (1992)

[30] R. Kaibyshev, F. Musin, E. Avtokratova, E. Motohashi, Mater. Sci. Eng. A 392, 373 (2005)
[31] E. Nembach, Particle Strengthening of Metals and Alloys (Wiley, New York, 1997)

[32] A.I. Karasevskii, V.V. Lubashenko, Phys. Status Solidi B 241, 1274 (2004)

[33] S.Y. Liem, G. Kresse, J.H.R. Clarke, Surf. Sci. 415, 194 (1998)

[34] X.M. Li, Y. Zou, Z.W. Zhang, Z.D. Zou, Mater. Trans. 51, 305 (2010)

[35] L. Ren, L. Nan, K. Yang, Mater. Des. 32, 2374 (2011)

[36] Q.F. Ma, R.S. Fang, L.C. Xiang, S. Guo, Handbook of Thermophysical Properties (China Agricultural Machine Press, Beijing, 1986). (in Chinese)

[37] F.L. Yaggee, E.R. Gilbert, J.W. Styles, J. Less-Comm. Met. 19, 39 (1969)

[38] T. Kunimine, T. Aragaki, T. Fujii, S. Onaka, M. Kato, J. Mater. Sci. 46, 4302 (2011)

[39] J.W. Martin, Precipitation Hardening, 2nd edn. (ButterworthHeinemann, Oxford, 1998), pp. 79-98

[40] D.B. Park, S.M. Hong, K.H. Lee, M.Y. Huh, J.Y. Suh, S.C. Lee, W.S. Jung, Mater. Charact. 93, 52 (2014)

[41] D.B. Park, M.Y. Huh, W.S. Jung, J.Y. Suh, J.H. Shim, S.C. Lee, J. Alloys Compd. 574, 532 (2013)

[42] P. Ou, H. Xing, J. Sun, Metall. Mater. Trans. A 46, 1 (2015) 